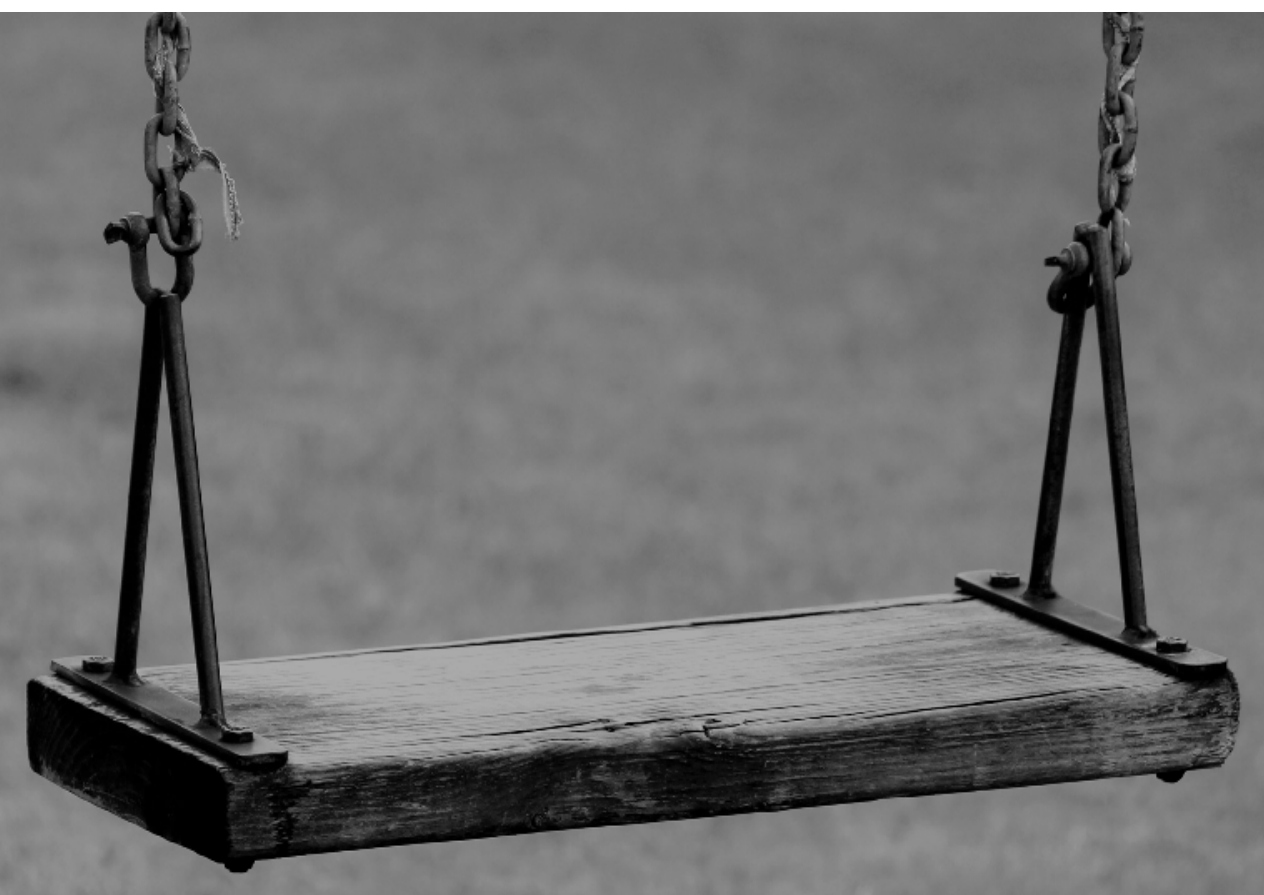

IMAGEM / IMAGEN: PXHere

\title{
Avaliação de reincidência de ofensa sexual cometida por adolescentes de 16-18 anos
}

\section{Ana Clara Gomes da Silva}

Universidade de Brasília, Curso de Psicologia, Brasília, Distrito Federal, Brasil https://orcid.org/0000-0003-4756-050X

\section{Larissa Martins de Mello Fernandez}

Universidade de Brasília, Curso de Psicologia, Brasília, Distrito Federal, Brasil https://orcid.org/0000-0002-9669-6211

\section{Ranieli Carvalho Gomes de Sousa}

Universidade de Brasília, Curso de Psicologia, Brasília, Distrito Federal, Brasil

https://orcid.org/0000-0002-1204-6562

\section{Vanessa de Moura Pereira}

Universidade de Brasília, Curso de Psicologia, Brasília, Distrito Federal, Brasil

https://orcid.org/0000-0001-7563-5340

\section{Andrea Schettino Tavares}

Universidade de Brasília, Programa de Pós-Graduação em Psicologia Clínica e Cultura, Brasília, Distrito Federal, Brasil https://orcid.org/0000-0002-4582-0526

\section{Liana Fortunato Costa}

Universidade de Brasília, Programa de Pós-Graduação em Psicologia Clínica e Cultura, Brasília, Distrito Federal, Brasil https://orcid.org/0000-0002-7473-1362 
A ofensa sexual é um fenômeno complexo que, embora seja amplamente discutido sob o ponto de vista da vitimização, ainda não contempla totalmente a perspectiva do circuito ofensivo. O preconceito em relação ao tema da ofensa sexual na perspectiva da autoria acaba por gerar uma falta de estudos e intervenções focadas em quem cometeu a ofensa sexual (DOMINGUES; COSTA, 2016), afetando também a compreensão em relação ao adolescente ofensor (EASTMAN; CRAISSATI; SHAW, 2019).

A literatura aponta um significativo crescimento, nas últimas décadas, no registro numérico de adolescentes que cometeram ofensas sexuais, representando cerca de um terço dos casos (BORGES; COSTA, 2020; TAVARES; MONTENEGRO, 2019). Em um estudo feito por Said (2017), que analisou 290 fichas de notificação de ofensa sexual e prontuários biopsicossociais, encontrou-se que o número de adolescentes que a cometeram representou $55 \%$ da amostra analisada. Esses dados corroboram a necessidade de investir em políticas públicas de intervenção para autores que iniciaram atos dessa natureza na adolescência, sobretudo em vista da possibilidade de reincidência criminal na vida adulta. Além disso, se, entre adolescentes que cometeram ofensas sexuais, as estatísticas e estudos são escassos, entre jovens adultos é ainda menor o desenvolvimento desse tipo de investigação no cenário brasileiro (EASTMAN; CRAISSATI; SHAW, 2019).

Este texto refere-se a uma pesquisa exploratória realizada com adolescentes entre 16 e 18 anos que cometeram ofensa sexual atendidos em um programa de assistência a famílias em situação de violência em uma capital da região Centro-Oeste do Brasil. O objetivo é investigar o risco de reincidência sexual dos participantes desse programa nessa faixa etária (completos em 2019) por meio do instrumento ERASOR ${ }^{1} 2.0$ (versão portuguesa) a partir das informações contidas nos registros dos prontuários.

\section{O adolescente ou o jovem adulto que cometeu ofensa sexual}

A juventude é uma importante etapa da vida em que ocorre a transição da adolescência para a vida adulta. Por não existir um consenso entre países e instituições sobre a definição de faixa etária entre adolescentes e jovens adultos, cada país e/ou instituição considera um intervalo de idade específico para identificar esse público. No Brasil, o Estatuto da Criança e do Adolescente (ECA) define como adolescentes as pessoas entre 12 e 18 anos de idade (BRASIL, 1990). Em relação aos jovens adultos, a lei do Estatuto da Juventude define como jovem quem tem entre 15 e 29 anos, sendo que, para pessoas entre 15 e 18 anos, a aplicação da lei se dá por meio do ECA (BRASIL, 2013).

Apesar de jovens adultos serem reconhecidos em sua maturidade civil e jurídica, o contexto atual da geração é marcado por uma transição emergente em relação à adolescência, na qual esses sujeitos, de maneira geral, ingressam no mercado de trabalho de forma tardia, o que pode implicar a saída tardia da casa de seus responsáveis (MOTA; ROCHA, 2012). O contexto do início da vida adulta repercute na autonomia financeira do jovem (ANDRADE, 2010), que pode ainda recorrer ao provimento de subsídios advindo das figuras parentais, implicando acordos de divisão de tarefas domésticas e cuidados

1 Estimate of Risk of Adolescent Sexual Offense Recidivism (Estimativa do Risco de Reincidência de Agressões Sexuais em Adolescentes). 
com crianças que residem na mesma casa. Essas diferentes características estão ligadas às condições socioeconômicas que ditam a emergência ou postergação por ganhos materiais, para si ou para auxílio à família. O contexto social de pertencimento, e/ou de sobrevivência, pode representar um acúmulo de riscos em relação à família e sociedade mais ampla, configurando uma sobrevivência que ameace, ofereça suporte ou incentive (OLIVEIRA et al., 2020). Não se pode generalizar esses cenários, mas é importante reconhecer novas configurações e demandas familiares.

Em intervenções realizadas com jovens adultos é viável ao profissional buscar conhecer a dinâmica familiar na qual estão inseridos, compreendendo o contexto e intervindo de acordo com a situação em que o adolescente/jovem adulto e sua família se encontram, além de realizar procedimentos com todos os integrantes do núcleo familiar. E, para além da família, compreendendo a adolescência como um período de vulnerabilidade, considera-se que vários fatores históricos e atuais - como geração presente, tempo, raça, etnia, desnaturalização das desigualdades, violência policial, discursos e práticas sociais e institucionais - concorrem para o reconhecimento de uma situação social que se constitui em um movimento retroalimentado (PEQUENO, 2020).

A legislação brasileira possui sistemas diferenciados de responsabilização para adolescentes e jovens adultos. O Sistema Nacional de Atendimento Socioeducativo (Sinase), que regulamenta a execução das medidas socioeducativas para adolescentes que cometeram ato infracional (BRASIL, 2012), prevê a responsabilização e o atendimento psicossocial do adolescente, de acordo com dois tipos de programas: os programas de meio aberto (advertência, obrigação de reparar o dano, prestação de serviços à comunidade e liberdade assistida) e os programas de privação de liberdade (semiliberdade e internação). Conforme o Art. $5^{\circ}$ do Código Civil brasileiro, a menoridade cessa para indivíduos com 18 anos completos, sendo assim, a responsabilização criminal de jovens adultos está de acordo com o disposto no Código Penal (BRASIL, 1940). O tempo de cumprimento das penas varia de acordo com cada caso e estão divididas em: privativas de liberdade, restritivas de direito ou multas.

A responsabilização criminal de jovens adultos é uma questão que vem sendo trabaIhada por diversos autores2. A literatura argumenta sobre o problema de considerar a idade cronológica como fator determinante para a decisão do tipo de julgamento oferecido para jovens (COSTA, 2016; TORRES, 2019). Embora a idade cronológica tenha um importante papel na diferenciação de adolescentes e jovens adultos, há outros elementos que precisam ser considerados para determinar a maturidade psíquica do indivíduo, como a sua fase de desenvolvimento humano e neurológico (BARBOSA, 2020; COSTA, 2016; EASTMAN; CRAISSATI; SHAW, 2019). Ishida (2015) traz em seu estudo a discussão de $o$ atendimento de jovens adultos ocorrer pelo sistema judicial adulto a partir dos 18 anos. A autora argumenta que processar e criminalizar jovens adultos de acordo com o sistema criminal adulto reduz as chances indivíduos se tornarem membros produtivos na sociedade, eleva as taxas de reincidência e superlotação de presídios, além de aumentar os custos para a sociedade pelo encarceramento e desemprego dessa população.

2 Cf. Eastman, Craissati e Shaw (2019); Ishida (2015); Ressel, Lyons e Romano (2018). 


\section{Um instrumento de avaliação de reincidência de ofensa sexual}

Este estudo foi realizado com base no instrumento ERASOR, um instrumento estruturado em checklist adaptado para a língua portuguesa pelos autores Barroso e Manita (2012a). O ERASOR ainda é pouco conhecido no contexto brasileiro. Entretanto, é notória a sua contribuição para um melhor atendimento prestado aos adolescentes que cometem ofensa sexual, uma vez que é possível identificar vulnerabilidades relacionadas ao ato infracional cometido (DOMINGUES, 2016). Assim, é possível estimar o risco de reincidência de uma nova ofensa sexual, estimar o melhor atendimento a ser oferecido, auxiliando os profissionais a compreenderem o contexto no qual o adolescente está inserido. A proteção e cuidados oferecidos a esses indivíduos contribuem para a decisão judicial sobre qual medida socioeducativa a ser aplicada.

Considerando-se esses aspectos, Barroso e Manita (2012b) destacam que o ERASOR deve ser preenchido por avaliadores (profissionais) que conheçam bem o instrumento e que tenham conhecimento e experiência de atendimento com adolescentes e suas famílias e ofensas sexuais. A notificação da ofensa sexual é a primeira ação a ser tomada para que o adolescente que cometeu tal ato, assim como a vítima, receba proteção e, em seguida, para que o autor da ofensa possa ser responsabilizado. Como salientam Domingues e Costa (2016), a notificação é tão importante para a vítima quanto para o adolescente que cometeu a ofensa, pois ambos precisam de cuidados. A família, por sua vez, também tem papel fundamental para que os adolescentes não venham a reincidir na ofensa sexual, por isso a necessidade de a família também ser parte do plano de atendimento, uma vez que a ofensa sexual pode ser um sintoma denunciador de conflitos familiares (BORGES; COSTA, 2020; DOMINGUES, 2016), visto que o contexto familiar de indivíduos que cometem ofensa sexual tende a ser marcado por violências físicas, negligência, rompimentos e distanciamento afetivo e autoritarismo (COSTA et al., 2017; FONSECA; COSTA, 2019; RESSEL; LYONS; ROMANO, 2018; SAID; COSTA, 2019), características que contribuem para a recidiva da ofensa sexual perpetrada pelo adolescente.

\section{Método}

\section{Contexto}

A pesquisa foi realizada em uma unidade de saúde de uma capital da região CentroOeste que atende pessoas em situação de violência sexual as quais chegam encaminhadas de outros serviços de saúde e de justiça ou por procura espontânea. A equipe de profissionais dessa unidade era composta por psicólogos e assistentes sociais, estudantes e residentes da área da saúde. O ciclo de atendimentos seguia as seguintes etapas: entrevistas de acolhimento, atendimento grupal e encaminhamentos pós-atendimento grupal. As entrevistas de acolhimento tinham o objetivo de contextualizar o serviço de saúde para os indivíduos atendidos e compreender o funcionamento psicossocial do adolescente e sua família e a dinâmica da violência cometida. O atendimento grupal era composto por sete sessões quinzenais, com agenda prévia e temáticas específicas. Os temas das sessões eram previamente definidos a partir de consulta à literatura, trajetória do oferecimento da ação psicossocial e estudos de casos. Acresciam-se ao processo reuniões periódicas com instâncias da área da infância, adolescência e juventude, como a Vara de Família, o Ministério Público e o Núcleo de Atenção à Violência da Secretaria de Saúde (COSTA; PENSO; CONCEIÇÃO, 2015). Rotineiramente, os temas propostos para a intervenção eram: proteção, transgeracionalidade, sexualidade, violência 
sexual, autoestima e projeto de namoro (COSTA, 2011; COSTA et al., 2015). Os encaminhamentos consistiam em atendimentos telefônicos para cada família e atendimentos presenciais conforme necessidade verificada pela equipe. É importante assinalar que essa rotina era padrão para tempos não pandêmicos. A equipe de pesquisa foi composta por uma orientadora acadêmica e cinco auxiliares de pesquisa: uma aluna de mestrado e quatro alunas de graduação de um curso de Psicologia.

Participantes

Foram consultadas e analisadas as informações registradas nos prontuários de 12 adolescentes em atendimento no ano de 2019. O critério de inclusão foi o adolescente ter entre 16 e 18 anos de idade, conforme objetivo da pesquisa. Todas as ofensas cometidas foram intrafamiliares, incluindo-se relações com a família extensa, conhecidos e vizinhos com interações rotineiras e diárias.

Instrumento

O instrumento utilizado foi o ERASOR 2.0, que é composto por um checklist de 25 fatores que avaliam os riscos com base em 5 categorias: (1) interesses, atitudes e comportamentos sexuais; (2) histórico de agressões sexuais; (3) funcionamento psicossocial; (4) contexto familiar; e (5) tratamento, além da possibilidade de indicar outros fatores para casos específicos (BARROSO; MANITA, 2012a). Cada um dos 25 fatores permite a indicação de: a) presente; b) provável/parcialmente presente; e c) ausente ou desconhecido no histórico de vida do adolescente. O apontamento "presente" diz respeito a ter sido possível observar aquele risco nas informações colhidas e/ou observadas. Do mesmo modo, o apontamento "provável/parcial" indica que o risco está informado de forma parcial; e o apontamento "ausente" indica que não há informação sobre aquele risco. Com base nessas indicações, pode-se formular uma estimativa de risco de reincidência baixo, moderado ou alto, sendo que a avaliação clínica realizada pelos profissionais também é importante na construção dessa estimativa. A decisão final vai depender da combinação de todos os fatores indicados no instrumento.

\section{Coleta das informações}

A coleta das informações para a pesquisa ocorreu durante o ano de 2020 em plena vigência da pandemia do novo coronavírus (COVID-19). Essa condição trouxe impasses na execução da pesquisa, não sendo possível reuniões presenciais para estudo e coletas das informações. As informações que serviram de base para o preenchimento do instrumento foram acessadas nos prontuários dos adolescentes. Esses prontuários continham todos os registros de todas as etapas do atendimento, desde o acolhimento até os contatos telefônicos após a ação grupal.

Utilizou-se o método de pesquisa documental, em que as pesquisadoras consultaram os prontuários de adolescentes entre 16 e 18 anos no período de agosto a outubro de 2020, referente ao atendimento no ano de 2019. Nos prontuários constavam informações a respeito de: dados gerais e psicossociais, ofensa cometida, vítimas, registros da entrevista de acolhimento, genograma, relatório do Ministério Público e registro de desenvolvimento da ação grupal de cada adolescente. Toda a orientação acadêmica e discussão sobre o acesso aos prontuários e retirada das informações ocorreu por via remota. 
O procedimento do acesso às informações aconteceu da seguinte forma: a equipe de profissionais da unidade separou os prontuários referentes aos adolescentes entre 16 e 18 anos que estavam em atendimento no ano de 2019; as pesquisadoras ( 5 auxiliares de pesquisa) e a equipe de profissionais organizaram horários para que o acesso presencial aos prontuários pudesse ser realizado em condições de segurança. Esse acesso ocorreu com uma dupla de pesquisadoras consultando o prontuário em oito encontros com duração de quatro horas cada. A pesquisa documental pode ser uma excelente fonte de informação, pois se trata de um registro perene, padronizado e que oferece menores possibilidades de coleta de erros. Entretanto, pode também ser um ato intrusivo, devendo haver cuidado ético na retirada das informações (BERG, 1998). Os prontuários não foram fotografados e permaneceram na unidade de saúde. A equipe de pesquisadoras tomou os devidos cuidados para registrar as informações de cada prontuário com números, e não com os nomes dos adolescentes, sendo que essas informações foram a base para posterior discussão por via remota com outras pesquisadoras e com a supervisora acadêmica. Todos os momentos presenciais de contato direto com os prontuários seguiram as normas de segurança da instituição, tendo sido evitadas aglomerações e sido utilizado o álcool em gel e máscara no período de permanência no local. Devido à continuidade da pandemia foram realizadas, durante três meses, sete reuniões virtuais com o intuito de discutir as informações coletadas, visando ao preenchimento do checklist ERASOR.

As informações coletadas nos prontuários foram organizadas em uma planilha para cada adolescente e, a partir dessas informações, realizou-se o preenchimento do instrumento. Foram realizadas reuniões virtuais reunindo as avaliadoras, e todos os itens foram discutidos após leitura das informações coletadas, sempre seguindo o formulário de codificação de cada critério do ERASOR. Dentre essas sete reuniões, a orientadora acadêmica participou de quatro. Em seguida, estimou-se o risco de reincidência de agressão sexual nesses adolescentes, o que também foi discutido entre a equipe.

\section{Análise das informações}

O ERASOR permite que, com base nas informações coletadas durante todo o processo de atendimento dos adolescentes (desde o acolhimento até encaminhamentos), sejam conhecidos os possíveis fatores de reincidência para cada adolescente. Nas cinco categorias que o instrumento avalia são apresentados critérios que indicam o possível risco. Na categoria de interesses sexuais, avalia-se o consumo excessivo de materiais pornográficos e a presença de fantasias recorrentes com crianças, se os adolescentes utilizaram ameaças verbais, físicas, psicológicas ao abordarem as vítimas e, nesse critério, as pesquisadoras optaram por incluir a sedução como forma de coação nessa abordagem. A utilização da sedução é importante porque funciona como imobilização para a criança que não possui experiência para lidar com essa atitude. Foi avaliado, ainda, se houve atitudes e justificativas por parte do adolescente que suportassem a ofensa cometida. Nesse caso, o grupo de avaliadores optou por incluir a negação de que a ofensa havia ocorrido como parte das justificativas. As análises consideraram o contexto da ofensa sexual no qual a sedução se apresenta como uma forma de se aproximar da vítima, e a negação de ter cometido a ofensa sexual permanece durante todo o processo da intervenção psicossocial. O processo de conversação e reflexão presente na intervenção pode apresentar um resultado de admissão por parte do adolescente em relação ao cometimento da ofensa sexual. Em relação à categoria de histórico 
de crimes, avaliam-se descrições das ofensas cometidas. Na categoria de funcionamento psicossocial, inclui-se avaliação dos vínculos com pares e desvios de condutas alheios ao cometimento de ofensas sexuais. A categoria de ambiente familiar permitiu reunir informações a respeito de como os familiares lidam e percebem a ofensa cometida pelo adolescente. Já o plano terapêutico se refere à participação no atendimento grupal como espaço de cuidado e reflexão a respeito de temáticas do momento de vida dos adolescentes nesse contexto.

Os riscos - avaliados em alto, moderado e baixo - foram classificados pelas avaliadoras de acordo com a pontuação de cada item das referidas categorias nos campos do instrumento: "presente", "provável ou parcialmente presente", "ausente" e também "desconhecido", ainda que diga respeito a informações que não constam no formulário de onde os dados foram coletados. Para a classificação de alto risco, considerou-se expressiva pontuação em condutas e interesses sexuais desviantes, baixo monitoramento dos responsáveis e baixa ou incompleta adesão dos familiares ao programa terapêutico da instituição. Todas as indicações de risco (alto, moderado, baixo) foram estabelecidas conforme as sugestões de interpretação do ERASOR (BARROSO; MANITA, 2012b).

A classificação de risco moderado perpassou a presença de interação com pares e engajamento dos familiares no monitoramento, proteção e adoção de estratégias preventivas para impedir novas ofensas, ainda que houvesse negação das ofensas, fatores estressores e baixa adesão ao programa terapêutico. Sobre a classificação de risco baixo, considerou-se a adesão completa ao programa terapêutico a presença de pessoas próximas ao adolescente que não fossem da família e de responsáveis engajados nos ambientes de convívio, bem como a presença de estratégias e planos para o futuro - como adesão escolar, inserção em programas direcionados ao mercado de trabalho e, ainda, a ausência de fatores estressores no convívio familiar ou de condutas e pares desviantes. Os resultados foram classificados de acordo com as referidas categorias de contexto do instrumento.

\section{Cuidados éticos}

O projeto de pesquisa foi submetido ao Comitê de Ética do Instituto de Ciências Humanas e Sociais, sendo aprovado com parecer $n^{\circ} 2.054 .880$, em 9 de maio de 2017, e emenda favorável $n^{\circ}$ 3.245.222, em 4 de abril de 2019. 
Os resultados são apresentados de duas formas. Primeiro são descritas as histórias dos adolescentes participantes e, em seguida, a Tabela 1 mostra a síntese da categorização dos 25 fatores do instrumento ERASOR de cada adolescente.

Adolescente 1: tinha 16 anos quando cometeu a ofensa sexual e, no ano de 2019, estava no $3^{\circ}$ ano do Ensino Médio (EM). Sofreu ofensa sexual aos oito anos, cometida pelos primos. Suas vítimas foram o irmão mais novo (8 anos), duas crianças cuidadas por sua mãe (3 e 4 anos), o irmão de um amigo (13 anos). $\mathrm{O}$ ambiente familiar era marcado por diversos conflitos. O pai, com comportamento de uso excessivo de álcool, ficou ausente em toda a situação da apreensão do adolescente, enquanto a mãe dizia que era uma fase e que a religião iria ajudar. O adolescente não possuía histórico de outros atos infracionais.

Adolescente 2: tinha 18 anos quando cometeu a ofensa sexual e, no ano de 2019, estava no $2^{\circ}$ ano do EM. Apresentava diagnóstico de déficit cognitivo e Transtorno do Déficit de Atenção com Hiperatividade (TDAH) e não havia informação sobre histórico de ofensa sexual na infância ou adolescência. Suas vítimas foram a sobrinha (9 anos) e a namorada do primo (16 anos). O pai assassinou a mãe e depois cometeu suicídio, com isso, o adolescente passou a ser cuidado pela tia e pelos avós, que davam constante suporte a ele. Não havia registro de outros atos infracionais.

Adolescente 3: tinha 16 anos quando cometeu a ofensa sexual e, no ano de 2019, estava no $1^{\circ}$ ano do EM, não possuindo histórico de ofensa sexual sofrida na infância ou adolescência. Sua vítima foi o primo (7 anos). Não havia registro de conflitos na família, e esta não acreditava na ocorrência da ofensa. Sem registro de outros atos infracionais ou uso de drogas.

Adolescente 4: tinha 16 anos quando cometeu a ofensa sexual e, no ano de 2019, estava no $7^{\circ}$ ano do Ensino Fundamental (EF). Não possuía histórico de ter sofrido ofensas sexuais e sua vítima foi a filha do cunhado (10 anos). Sem registro de conflitos no ambiente familiar e outros atos infracionais.

Adolescente 5: tinha 16 anos quando cometeu a ofensa sexual e, no ano de 2019, estava no $8^{\circ}$ ano do EF. Sofreu ofensa sexual na infância, cometida por um desconhecido, quando tinha 12 anos. Suas vítimas foram duas sobrinhas ( 3 e 4 anos) e um sobrinho (7 anos). O ambiente familiar era marcado por conflitos entre o adolescente e o padrasto, a mãe sofria violência física e psicológica e a família também se encontrava em situação de vulnerabilidade social. Sem registro de outros atos infracionais.

Adolescente 6: tinha 17 anos quando cometeu a ofensa sexual e, no ano de 2019, estava no $2^{\circ}$ ano do EM, sem registro de ofensa sexual sofrida. Sua vítima foi uma parente (30 anos) e adolescentes da mesma escola. Não havia registro de conflitos no ambiente familiar nem de outros atos infracionais ou uso de drogas. 
Adolescente 7: tinha 17 anos quando cometeu a ofensa sexual e, no ano de 2019, apresentava um atraso escolar, cursava a $3^{\mathrm{a}} / 4^{\mathrm{a}}$ série da Educação para Jovens e Adultos (EJA), com abandono por faltas. Sem registro de ofensa sexual sofrida. Apresentava ideação suicida e pensamentos negativos. Sua vítima foi uma vizinha idosa. A família encontrava-se em situação de vulnerabilidade social, sem registro de conflitos, mas sem acreditar na ocorrência da ofensa. Ausência de registro de outros atos infracionais ou uso de drogas.

Adolescente 8: tinha 16 anos quando cometeu a ofensa sexual e, no ano de 2019, estava no $8^{\circ}$ ano do EF. Sem registro de histórico de ofensas sexuais, de conflitos na família e outros atos infracionais. Suas vítimas foram duas primas (9 e 11 anos).

Adolescente 9: tinha 17 anos quando cometeu a ofensa sexual e, no ano de 2019, estava no $2^{\circ}$ ano do EM, tendo sofrido ofensa sexual pelo tio quando tinha 9 anos. A vítima do adolescente foi o irmão de um amigo (8 anos). Havia registro de diversos conflitos no ambiente familiar e violência doméstica sofrida pela mãe, como também de furto e uso de droga pelo adolescente.

Adolescente 10: tinha 17 anos quando cometeu a ofensa sexual e, em 2019, estava no $2^{\circ}$ ano do EM. Sofreu ofensa sexual aos 6 anos por adolescentes vizinhos. Sua vítima foi sua irmã (10 anos), que era violentada desde quando o adolescente tinha 15 anos. $O$ ambiente familiar era marcado por conflitos e violência doméstica sofrida pela mãe e a família se encontrava em situação de vulnerabilidade social. Sem registro de outros atos infracionais ou uso de drogas.

Adolescente 11: tinha 17 anos quando cometeu a ofensa sexual e não frequentava mais a escola, tendo abandonado os estudos no $8^{\circ}$ ano do EF. Sem registro de ofensa sexual sofrida. Sua vítima foi o vizinho de sua tia ( 8 anos), que ele violentou juntamente com o primo de 16 anos. O ambiente familiar era marcado por conflitos entre o adolescente e sua mãe e a família estava em situação de vulnerabilidade social. O adolescente possuía histórico de furtos, roubos e uso de drogas.

Adolescente 12: tinha 16 anos quando cometeu a ofensa sexual e, no ano de 2019, estava no EF, apresentando atraso escolar em razão de TDAH e do Distúrbio do Processamento Auditivo Central (DPAC). Sem registro de ofensa sexual sofrida, de conflitos familiares e de outros atos infracionais cometidos ou de uso de drogas. Sua vítima foi o primo ( 5 anos) e a família não acreditava na ocorrência da violência.

A seguir, apresenta-se a quantidade de registros (Tabela 1) que possibilitou indicar o risco de reincidência dos adolescentes. Os riscos foram classificados da seguinte forma: alto risco (AR) - três adolescentes $(1,2,10)$; moderado risco $(M R)$ - sete adolescentes $(3,5,7,8,9,11,12)$; baixo risco $(B R)$ - dois adolescentes $(4,6)$. 


\begin{tabular}{|c|c|c|c|c|c|c|c|c|c|c|c|c|c|}
\hline \multicolumn{14}{|c|}{ Adolescentes } \\
\hline Fatores & 1 & 2 & 3 & 4 & 5 & 6 & 7 & 8 & 9 & 10 & 11 & 12 & Categorias \\
\hline Presente & 4 & 1 & 3 & 3 & 1 & 3 & 1 & 3 & 3 & 3 & 3 & 3 & \multirow{4}{*}{$\begin{array}{l}\text { Interesses } \\
\text { sexuais, atitudes } \\
\text { e comportamentos }\end{array}$} \\
\hline Provável/ parcialmente & 0 & 1 & 0 & 0 & 1 & 0 & 1 & 0 & 1 & 0 & 0 & 0 & \\
\hline Ausente & 0 & 1 & 1 & 0 & 2 & 0 & 2 & 1 & 0 & 0 & 1 & 1 & \\
\hline Desconhecido & 0 & 1 & 0 & 1 & 0 & 1 & 0 & 0 & 0 & 1 & 0 & 0 & \\
\hline Presente & 5 & 7 & 5 & 2 & 6 & 4 & 2 & 5 & 3 & 5 & 4 & 4 & \multirow{4}{*}{ Histórico de crimes } \\
\hline Provável/ parcialmente & 0 & 0 & 0 & 0 & 1 & 0 & 0 & 0 & 0 & 0 & 0 & 0 & \\
\hline Ausente & 1 & 2 & 4 & 4 & 2 & 4 & 6 & 3 & 6 & 4 & 4 & 5 & \\
\hline Desconhecido & 3 & 0 & 0 & 3 & 0 & 1 & 1 & 1 & 0 & 0 & 1 & 0 & \\
\hline Presente & 1 & 1 & 0 & 0 & 0 & 0 & 1 & 0 & 0 & 0 & 1 & 0 & \multirow{4}{*}{$\begin{array}{c}\text { Funcionamento } \\
\text { psicossocial } \\
\text { (desviante) }\end{array}$} \\
\hline Provável / parcialmente & 1 & 1 & 0 & 0 & 1 & 0 & 1 & 1 & 2 & 0 & 1 & 1 & \\
\hline Ausente & 2 & 0 & 3 & 4 & 2 & 6 & 2 & 3 & 2 & 5 & 3 & 3 & \\
\hline Desconhecido & 2 & 4 & 3 & 2 & 3 & 0 & 2 & 2 & 2 & 1 & 1 & 2 & \\
\hline Presente & 4 & 2 & 1 & 0 & 1 & 1 & 3 & 0 & 3 & 1 & 2 & 1 & \multirow{4}{*}{$\begin{array}{c}\text { Funcionamento } \\
\text { familiar/ ambiental } \\
\text { (estressante) }\end{array}$} \\
\hline Provável/ parcialmente & 0 & 1 & 0 & 1 & 1 & 0 & 0 & 1 & 1 & 1 & 0 & 1 & \\
\hline Ausente & 0 & 1 & 3 & 3 & 2 & 3 & 1 & 3 & 0 & 2 & 2 & 2 & \\
\hline Desconhecido & 0 & 0 & 0 & 0 & 0 & 0 & 0 & 0 & 0 & 0 & 0 & 0 & \\
\hline Presente & 1 & 0 & 0 & 0 & 0 & 0 & 1 & 0 & 0 & 0 & 1 & 0 & \multirow{4}{*}{$\begin{array}{c}\text { Intervenção/ } \\
\text { Programa terapêutico }\end{array}$} \\
\hline Provável/ parcialmente & 1 & 0 & 1 & 0 & 0 & 1 & 0 & 0 & 1 & 1 & 0 & 1 & \\
\hline Ausente & 0 & 1 & 1 & 1 & 2 & 1 & 0 & 2 & 1 & 1 & 0 & 1 & \\
\hline Desconhecido & 0 & 1 & 0 & 1 & 0 & 0 & 1 & 0 & 0 & 0 & 1 & 0 & \\
\hline Riscos & A & A & M & B & $M$ & B & M & $M$ & $M$ & A & $\mathbf{M}$ & $M$ & \\
\hline
\end{tabular}

Fonte: dados da pesquisa.

Nota: $\mathrm{A}=$ alto risco; $\mathrm{M}=$ moderado risco; $\mathrm{B}=$ baixo risco. 
Buscando traçar um panorama de semelhanças e particularidades, inicia-se a discussão considerando o conjunto das histórias em relação ao ambiente sociofamiliar, às condições de vulnerabilidades na sobrevivência e à questão da ofensa sexual. Ressalta-se que este estudo enfoca uma faixa de idade relativa ao final da adolescência. Foram 12 participantes e destaca-se a dificuldade de obtenção dessas histórias em face de que essa população de adolescentes e familiares já estão inseridos no sistema judicial. Essa condição resulta em muitos preconceitos, medos e reservas em fornecer informações (WOLFF et al., 2016).

São 12 histórias de muito sofrimento, rompimentos afetivos, dificuldades, porém se observam aspectos positivos e situações familiares relativamente preservadas. A maior parte dos adolescentes frequentava a escola, todavia apresentando significativo atraso em relação à idade/ano escolar, e somente um adolescente estava fora da escola. Alguns adolescentes que apresentavam esse atraso tinham dificuldades orgânicas e de aprendizagem, e todos os participantes eram pertencentes a comunidades de baixa renda, com vulnerabilidade social indicada (SPILBURY; KORBIN, 2013). Foi possível observar relações familiares conflituosas, uso excessivo de drogas na geração do adolescente e na anterior, várias violências, como assassinato, suicídio, ofensa sexual e negação da família em aceitar o cometimento da ofensa sexual pela qual o adolescente estava em atendimento. Foram narrados conflitos familiares, mas também sua ausência, embora tenham sido percebidas situações de abandono dos adolescentes em relação às pessoas que deveriam ser seus cuidadores.

Uma particularidade foi a expectativa da solução da situação de ofensa sexual pela ação da religião sobre o adolescente ou, mais precisamente, pela possível influência do religioso de maior autoridade. As famílias optavam por manter em segredo a violência intrafamiliar, preferindo uma resolução que não envolvia outras instituições. Assim, algumas famílias silenciaram sobre o assunto ou isolaram o adolescente da vítima para evitar o convívio ou, ainda, aplicaram punições, como castigos físicos e psicológicos. Houve, ainda, as que tentaram encontrar ajuda na religião e colocaram o adolescente sob a orientação direta da autoridade religiosa (BORGES; COSTA, 2020; COSTA, 2011; FONSECA; COSTA, 2019). Quando isso acontece, corre-se o risco de não haver responsabilização na justiça, porque a "punição" é determinada por essa autoridade.

O espectro de idades das vítimas foi bastante extenso, atingindo faixas etárias desde a infância, adolescência, juventude, adultez e velhice. Do mesmo modo, o número de vítimas por adolescente abrangeu de uma vítima a quatro. Oito adolescentes ofenderam sexualmente somente uma vítima; dois adolescentes, duas vítimas; um adolescente, três vítimas; e um adolescente, quatro vítimas. A maior parte cometeu ofensa sozinho, mas há uma ofensa cometida juntamente com um parceiro. Todas as vítimas eram pertencentes ao convívio familiar do adolescente, sendo que não houve maiores detalhes sobre o período e a repetição da ofensa sexual cometida, exceto em um caso, que aponta a duração de três anos. Essas observações indicam o que os autores referência na área falam sobre a inexistência de um perfil determinado de quem comete ofensas sexuais, sejam adultos ou adolescentes. Entende-se que a ofensa sexual cometida é complexa e está inserida nas situações facilitadoras ou não do seu cometimento, sendo mais observadas ofensas de caráter oportunista (BORGES; COSTA, 2020; OLIVER, 2007). Para a continuidade da discussão, as informações foram organizadas conforme os fatores estressantes que potencializam ou não a reincidência da ofensa sexual. 
Relações familiares - A indicação de AR foi caracterizada pela significativa presença de fatores estressantes no ambiente familiar e disfuncionalidades psicossociais. Para os adolescentes com a indicação de MR houve baixa prevalência de fatores estressantes no ambiente familiar. A preservação de relações sociais com pares pode ser um fator que atenua o AR, com existência de conflitos familiares, como, por exemplo, em dois adolescentes que se inseriram no grupo de BR. Dos 12 adolescentes, os 3 que apresentaram AR possuíam histórico de presenciarem e/ou participarem de graves conflitos intrafamiliares, violências fatais, dificuldades de comunicação verbal, de vinculação afetiva com figuras parentais. Para esses três adolescentes, a figura paterna estava ausente, sendo um deles órfão devido ao feminicídio da mãe, causado pelo pai - seguido de autoextermínio. Dadas as relações de interdependência do adolescente com seu ambiente familiar, Fonseca e Costa (2019) afirmam que é imprescindível a compreensão da vulnerabilidade e da proteção oferecida nos contextos nos quais os adolescentes transitam, porque essa condição também se caracteriza por ser de vitimização (YODER; GRADY; PRECHT, 2019).

Na Tabela 1, sobre a categoria Funcionamento Familiar, o critério "desconhecido" apresenta indicação zero para todos os adolescentes, ou seja, a interação familiar está sendo percebida em sua qualidade, as condições de interação não passam despercebidas ou podem ser negligenciadas. Pode-se inferir com maior segurança que a qualidade da interação familiar representa um item primordial para a constituição da vulnerabilidade da ofensa sexual. Trata-se de uma situação na qual os adolescentes estão dentro de uma rotina sem supervisão parental ou com pouca qualidade, falta de adultos cuidadores mesmo na faixa etária entre 16 e 18 anos. A ausência de supervisão parental ou o fato de o adolescente cumprir função de cuidados de crianças constituem-se em configurações familiares que contribuem para a ocorrência da ofensa sexual (BORGES; COSTA, 2020; COSTA et al., 2017; EASTMAN; CRAISSATI; SHAW, 2019; OLIVER, 2007).

Vulnerabilidades sociais - As condições de vulnerabilidade social podem estar vinculadas ao envolvimento de outros atos infracionais (de natureza social) além do cometimento da ofensa sexual, assim como ao uso de álcool e outras drogas, indicando MR. Dos 12 adolescentes, 9 apresentaram condição socioeconômica de baixa renda, sendo 2 destes em condição de pobreza (mais grave), e as famílias dependiam de repasse de auxílio financeiro governamental. Costa et al. (2017) atentam para a importância de compreender como a pobreza financeira e a derivada violação de direitos básicos afetam as configurações familiares, trazendo um cenário que favorece o cometimento de ofensas sexuais.

A vulnerabilidade social na faixa etária dos 16 aos 18 anos ganha um contorno mais comprometido, pois esses adolescentes já estão com grande distanciamento de seus cuidadores, mais agregados a seus pares e com urgente necessidade de ganho financeiro para concretização de sua afirmação social (EASTMAN; CRAISSATI; SHAW, 2019). Assim, o risco de cometimento de outros atos infracionais aumenta, e nas histórias de vida aparecem roubo, furto, evidenciando uma trajetória de entrada (e talvez permanência) no sistema judicial e possível continuidade no sistema penal - após os 18 anos de idade. A questão é que com a morosidade das ações de atenção jurídica e psicossocial a esses adolescentes há o risco de eles alcançarem idade adulta ainda sem uma ação terapêutica que interfira na continuidade delitiva (DOMINGUES; COSTA, 2016). 
Interesses sexuais - É importante compreender o que significa interesse sexual para melhor pontuação deste item. Não se trata somente de como ocorre o momento do despertar da sexualidade, mas sim de interesse sexual desviante, ou seja, masturbação compulsiva, uso crônico e compulsivo de pornografia, linguagem e gestos altamente sexualizados frequentes e atividade sexual indiscriminada. A maioria dos adolescentes cometeu ofensa sexual com vítimas com diferença etária significativa, o que implica dominação e maior dificuldade de a vítima se defender. Wijetunga et al. (2016) encontraram que a presença de traços antissociais em adolescentes pode predizer reincidência de ofensa sexual com maior precisão se comparados a características de desejo sexual. Em relação a esta categoria, os três adolescentes com a indicação de AR apresentaram entre quatro e três vezes mais fatores "presentes" na marcação do instrumento - condição análoga à dos adolescentes do grupo de MR que receberam marcações com o máximo de três registros "presentes". Essas informações sugerem que os adolescentes de MR se diferenciam dos adolescentes com a indicação de AR por apresentarem preservação, principalmente, do funcionamento familiar. Isto é, há ainda relações de vinculação afetiva e presença de autoridade permeando as interações entre o membro da família com papel de cuidador e o próprio adolescente (COSTA et al., 2017; FONSECA; COSTA, 2019; OLIVER, 2007).

Destaca-se um aspecto que fortalece a atração por atividades de cunho sexual: a facilidade de acesso à pornografia. Tavares e Montenegro (2019) encontraram, em uma experiência de ação psicossocial com adolescentes que cometeram ofensa sexual e suas famílias, um reconhecimento de que meninos a partir de 10/11 anos já obtêm acesso fácil à pornografia por meio de participação e contato com outros adolescentes com idade um pouco superior. Considera-se que os adolescentes a partir de 16 anos possuem mais liberdade e autonomia, com mais oportunidades e condições de acesso a conteúdos pornográficos. Os adolescentes relatam que têm acesso à pornografia por meio dos amigos e parentes mais velhos, sendo a partir desse tipo de acesso que "aprendem" sobre sexualidade (além do que é ensinado na escola), pois não têm um ambiente adequado nem pessoas disponíveis para conversar e orientar sobre as dúvidas que surgem sobre a sexualidade e seu desenvolvimento (MACEDO; CONCEIÇÃO, 2015; TAVARES; MONTENEGRO, 2019). Com um contexto sem orientação e supervisão, o acesso a conteúdos inadequados e violentos para a fase de desenvolvimento em que se encontram pode influenciar na maneira como é construída a sexualidade desse adolescente e seus comportamentos (MANOEL et al., 2020). Manoel et al. (2020) apresentam essa problemática trazendo um desafio para a atualidade da Psicologia. O acesso à deep web (sítios de pornografia, imagens sexuais, vídeos/fotos de ofensa sexual contra crianças/adolescentes) necessita ser incorporado ao conhecimento de profissionais para que se viabilize a melhor compreensão da situação.

Participação no atendimento psicossocial - Um olhar sobre o cômputo geral das avaliações indica que sete adolescentes foram avaliados como de MR por reincidirem na ofensa sexual após o período da intervenção grupal. Para Barroso e Manita (2012a), são poucos os adolescentes que cometem uma nova ofensa quando há um tratamento específico para o cometimento de crime sexual. No entanto, os programas para evitar reincidência da ofensa ainda necessitam de mais pesquisas e adequação das intervenções em cada situação (EASTMAN; CRAISSATI; SHAW, et al., 2019; POOLEY, 2020). Estudos mostraram que adolescentes de faixa etária menor apresentam mais possibilidades de predição de riscos, pois exibem maior responsividade a fatores como impulsividade e traços antissociais, de acordo com as escalas e instrumentos, estando em conformidade com o ERASOR (DOMINGUES, 2016; WIJETUNG et al., 2016). 
Contudo, adolescentes nessa faixa possuem maior flexibilidade a processos interventivos se comparados aos mais velhos, ainda que adolescentes a partir dos 16 anos apresentem características de personalidade mais estáticas, considerando a proximidade da vida adulta. Nesse sentido, essa faixa etária estaria menos suscetível a modificações advindas de processos interventivos. Rojas e Oliver (2019) investigaram as mudanças de um processo interventivo ambulatorial em adolescentes que cometeram a ofensa entre 14 e 16 anos, encontrando resultados indicativos da presença de mudança ao longo da intervenção. Esses autores sugerem que tais processos devem ser aferidos ao longo de seu desenvolvimento a fim de se encontrar os fatores que motivaram o engajamento e a abertura a mudanças.

$\mathrm{Na}$ categoria de análise Intervenção/programa terapêutico busca-se compreender a qualidade da participação do adolescente na recém-findada intervenção. Foi encontrado que o critério "parcialmente presente" foi o mais frequente, e o critério "presente", o menos frequente, significando que os adolescentes não se mostraram assíduos e participantes de todas as sessões. Essa condição já é esperada, visto que o conjunto de adolescentes que comete ofensa sexual é encaminhado para atendimento sob obrigação, e não apresenta demanda para a atividade. Vários desses adolescentes também estão sendo acompanhados pelo Ministério Público, o que traz algumas peculiaridades para o processo, porque os promotores mantêm comunicação e interesse na execução do programa.

Os resultados dessas avaliações de risco mostraram que as propostas de intervenção que vêm sendo desenvolvidas na unidade oferecem impactos diferentes para os adolescentes com menos de 16 anos e aqueles de 16 a 18 anos. Somente dois adolescentes obtiveram uma avaliação de $B R$, e pode-se inferir que o programa não oferece um escopo suficiente para diminuir o risco de reincidência entre os adolescentes de 16 a 18 anos de idade, todavia, seria necessária uma avaliação formal da intervenção e uma comparação entre esses dois grupos para averiguar. Entretanto, não é esse o objetivo do texto.

\section{Desafio: atendimento à adolescência tardia no cometimento da ofensa sexual}

A faixa etária dos adolescentes em destaque neste texto mostra uma questão muito importante para a avaliação das condições de risco de reincidência e para a construção de intervenções eficientes. Sabe-se que a adolescência é um período de grandes mudanças no âmbito corporal e social, especialmente em relação ao amadurecimento sexual. Essa fase do desenvolvimento humano possibilita vivenciar uma série de comportamentos de risco como uma forma de adquirir experiências necessárias para a construção da identidade (BORGES; COSTA, 2020; EASTMAN; CRAISSATI; SHAW, 2019). Na realidade sociocultural brasileira, é necessário comentar sobre o desrespeito aos direitos humanos de crianças e adolescentes e as frágeis políticas de proteção que são adotadas, apesar dos 30 anos de promulgação do ECA (PEQUENO, 2020). Mesmo que esses jovens estejam sob alguma dimensão de proteção, o fato de estarem envolvidos em ambientes que favoreçam a reincidência ou que apresentem outros comportamentos de risco colabora para que futuramente haja um agravamento de tais condições. Além disso, Wijetunga et al. (2016) sugerem que fatores relativos ao funcionamento psicossocial, se combinados a fatores sociais de risco, como a relação entre pares e o convívio familiar, culminam na reincidência. Esses mesmos autores explicam que o desenvolvimento disfuncional da sexualidade entre parceiros da mesma idade pode levar ao exercício da sexualidade de forma impulsiva, desdobrando-se em ofensas sexuais em indivíduos de outras faixas etárias. 
O presente estudo mostrou que, para a faixa etária de 16-18 anos, o instrumento ERASOR mostra-se útil na construção de um melhor atendimento, sendo possível obter informações amplas sobre os adolescentes, investigar em quais campos as intervenções foram suficientes para evitar a reincidência e identificar as suas principais dimensões de proteção (DOMINGUES, 2016). Portanto, ainda que avalie possíveis riscos de reincidência, com um caráter avaliativo e informativo, esse instrumento pode conter aspectos reflexivos e compreensivos que venham a ser úteis em outros contextos, para além do interventivo/terapêutico.

\section{Considerações finais}

O texto buscou conhecer a aplicação e avaliação do instrumento ERASOR que auxilia na compreensão das condições de vulnerabilidade para o cometimento de ofensa sexual e/ou sua reincidência no contexto da faixa etária de 16 a 18 anos. À medida que o instrumento for adaptado para a realidade brasileira e ficar mais conhecido, acredita-se que os critérios do formulário poderão melhor atender às especificações socioculturais nas quais esses adolescentes estão inseridos.

Observaram-se limitações para a aplicação do instrumento, mormente em tempos da pandemia de COVID-19. Em termos de aplicação rotineira, o instrumento teria várias fases de pontuação e decisão conjunta a partir de observações em: registros contidos nos prontuários, interações dos adolescentes e seus familiares, falas e diálogos presentes na ação grupal, considerações realizadas por cada profissional que manteve contato com os adolescentes e discussão final sobre a atribuição da qualidade do risco envolvendo todos os membros da equipe. Evidentemente, essa sequência não pode ser realizada em função da situação de segurança frente à questão sanitária. Esse cenário dificultou o acesso das pesquisadoras à equipe, que se manteve operando com demanda aumentada e na modalidade de rodízio - com um ou dois profissionais presentes na unidade de saúde por dia, enquanto os outros permaneciam em trabalho remoto.

Acredita-se que um maior contato com os profissionais responsáveis pelo atendimento poderia enriquecer a análise das informações, com melhor compreensão da dinâmica familiar dos adolescentes, dos fatores relacionados ao funcionamento social voltado aos pares e outras atividades extraescolares e extrafamiliares de suporte psicossocial. Ainda assim, considera-se que este estudo, de caráter exploratório, identifica a potencialidade do instrumento para o melhor conhecimento sobre os adolescentes nessa faixa etária.

\section{REFERÊNCIAS BIBLIOGRÁFICAS}

ANDRADE, C. Transição para a idade adulta: das condições sociais às implicações psicológicas. Análise Psicológica, v. 28, n. 2, p. 255-267, 2010.

BARBOSA, M. A. O tratamento jurídico da delinquência dos jovens adultos. 2020. Dissertação (Mestrado em Direito) - Faculdade de Direito, Escola do Porto, Universidade Católica Portuguesa, Porto, 2020.

BARROSO R. G.; MANITA, C. ERASOR: sugestões de interpretação de avaliações de risco global. Estimativa de risco de reincidência de agressão sexual em adolescentes. Versão portuguesa 2.0. 2012b.

.ERASOR: sugestões de interpretação de avaliações de risco global. Estimativa de risco de reincidência de agressão sexual em adolescentes. Versão portuguesa 2.0. 2012b. 
BERG, B. L. Qualitative research methods for the social sciences. 3. ed. Needham Heights: Alleph and Bacon, 1998.

BORGES, M. M.; COSTA, L. F. Adolescentes ofensores sexuais atendidos em uma instituição de saúde do Centro-Oeste do Brasil. Arquivos Brasileiros de Psicologia, v. 72, n. 1, p. 140-158, 2020.

BRASIL. Decreto-Lei $\mathbf{n}^{\circ}$ 2.848, de 7 de dezembro de 1940. Código Penal Brasileiro. Brasília, 1940. Disponível em: <http://www.planalto.gov.br/ccivil_03/decreto-lei/Del2848. htm>. Acesso em: 14 maio 2021.

BRASIL. Lei no 8.069, de 13 de julho de 1990. Dispõe sobre o Estatuto da Criança e do Adolescente e dá outras providências. Brasília, 1990. Disponível em: <http://www. planalto.gov.br/ccivil_03/leis/l8069.htm>. Acesso em: 12 maio 2021.

BRASIL. Lei no 12.594, de 18 de janeiro de 2012. Institui o Sistema Nacional de Atendimento Socioeducativo (Sinase), regulamenta a execução das medidas socioeducativas destinadas a adolescente que pratique ato infracional. Brasília, 2012. Disponível em: <http://www.planalto.gov.br/ccivil_03/_ato2011-2014/2012/lei//12594.htm>. Acesso em: 14 maio 2021.

BRASIL. Lei no 12.852, de 5 de agosto de 2013. Institui o Estatuto da Juventude e dispõe sobre os direitos dos jovens, os princípios e diretrizes das políticas públicas de juventude e o Sistema Nacional de Juventude - SINAJUVE. Brasília, 2013. Disponível em: <http://www.planalto.gov.br/ccivil_03/_Ato2011-2014/2013/Lei/L12852. htm>. Acesso em: 12 maio 2021.

COSTA, H. M. M. Responsabilidade criminal na adolescência: contributo(s) da Psicologia do Desenvolvimento no âmbito da justiça de menores. Revista lurisprudentia, v. 5 , n. 9, p. 147-169, 2016.

COSTA, L. F. Participação de famílias no Grupo Multifamiliar de adolescentes ofensores sexuais: vergonha e confiança. Psicologia Clínica, v. 23, p. 185-201, 2011.

COSTA, L. F.; PENSO, M. A.; CONCEIÇÃO, M. I. G. Manual de Grupos Multifamiliares. Brasília: Central de Produções Gráficas e Editora, 2015.

COSTA, F. et al. Transmisión generacional familiar en adolescentes que cometieron ofensa sexual. Psicologia: Ciência e Profissão, v. 37, n. 4, p. 995-1010, 2017.

DOMINGUES, D. F. Adolescentes em situação de ofensa sexual intrafamiliar: conhecer e intervir para prevenir a reincidência. 2016. Tese (Doutorado em Psicologia) - Programa de Pós-Graduação em Psicologia Clínica e Cultura, Universidade de Brasília, Brasília, 2016.

DOMINGUES, D. F.; COSTA, L. F. O adolescente em situação de ofensa sexual: proteção e responsabilização para evitar a reincidência. Revista Psicologia Política, v. 16, n. 36, p. 139-151, 2016.

EASTMAN, O.; CRAISSATI, J.; SHAW, J. Young adult sexual offenders with emerging personality disorders: developmental and offence-related characteristics and treatment engagement. Journal of Sexual Aggression, v. 25, n. 2, p. 105-115, 2019.

FONSECA, M. D. C. F.; COSTA, L. F. Desconhecido perigoso: a relação entre o adolescente ofensor sexual e sua mãe. Pensando Famílias, v. 23, n. 2, p. 223-239, 2019.

ISHIDA, K. Young adults in conflict with the law: opportunities for diversion. Dialogue, Education \& Advocacy, v. 7, p. 1-15, 2015. 
MACEDO, E. O. S.; CONCEIÇÃO, M. I. G. Significados sobre la adolescencia y la salud entre los participantes de un grupo educativo de adolescentes. Psicologia: Ciência e Profissão, v. 35, n. 4, p. 1059-1073, 2015.

MANOEL, D. F. et al. Sexting e adolescência: a emergência de novos temas para Psicologia do desenvolvimento. Revista da ESPAGESP, v. 21, n. 1, p. 37-50, 2020.

MOTA, C. P.; ROCHA, M. Adolescência e jovem adultícia: crescimento pessoal, separaçãoindividuação e o jogo das relações. Psicologia: Teoria e Pesquisa, v. 28, n. 3, p. 357-366, 2012.

OLIVEIRA, C. et al. "Sobrevivendo": vulnerabilidade social vivenciada por adolescentes em uma periferia urbana. Interface - Comunicação, Saúde, Educação, v. 24, e190813, 2020.

OLIVER, B. E. Three steps to reducing child molestation by adolescents. Child Abuse \& Neglect, v. 31, p. 683-689, 2007.

PEQUENO, L. S. Homicídios na adolescência e questão social: análise sobre estado de exceção e violência letal contra adolescentes. Revista Humanidades em Perspectivas, v. 2, n. 4, p. 229-243, 2020.

POOLEY, K. What are the characteristics of effective youth offender programs? Trends \& Issues in Crime \& Criminal Justice, n. 604, p. 1-22, 2020.

RESSEL, M.; LYONS, J.; ROMANO, E. Abuse characteristics, multiple victimization and resilience among young adult males with histories of childhood sexual abuse. Child Abuse Review, v. 27, n. 3, p. 239-253, 2018.

ROJAS, E. Y.; OLVER, M. E. Validity and reliability of the violence risk scale-youth sexual offense version. Sexual Abuse, v. 32, n. 7, p. 826-849, 2020.

SAID, A. P. Abuso sexual de vítimas do sexo masculino: notificações e prontuários no Distrito Federal. 2017. Dissertação (Mestrado em Psicologia) - Programa de Pós-Graduação em Psicologia Clínica e Cultura, Universidade de Brasília, Brasília, 2017.

SAID, A. P.; COSTA, L. F. Family dynamics of boys victims of sexual abuse. Paidéia, v. 29, p. 1-9, 2019.

SPILBURY, J. C.; KORBIN, J. E. Social networks and informal social support in protecting children from abuse and neglect. Child Abuse \& Neglect, v. 37, p. 8-16, 2013.

TAVARES, A. S.; MONTENEGRO, N. M. S. Intervenção psicossocial com adolescentes que cometeram ofensa sexual e suas famílias: o Grupo Multifamiliar. Nova Perspectiva Sistêmica, v. 64, p. 82-104, 2019.

TORRES, S. B. S. Criminalização da juventude pelo Estado. 2019. Monografia (Graduação em Serviço Social) - Departamento de Serviço Social, Universidade Federal do Rio Grande do Norte, Natal, 2019.

WIJETUNGA, C. et al. The influence of age and sexual drive on the predictive validity of the juvenile sex offender assessment protocol-revised. International Journal of Offender Therapy and Comparative Criminology, v. 62, n. 1, p. 150-169, 2016.

WOLFF, L. S. et al. O recurso psicodramático na intervenção com o adulto autor de ofensa sexual. Revista Brasileira de Psicodrama, v. 24, n. 2, p. 58-68, 2016.

YODER, J.; GRADY, M. D.; PRECHT, M. Relationships between early life victimization, antisocial traits, and sexual violence: executive functioning as a mediator. Journal of Child Sexual Abuse, v. 28, n. 6, p. 667-689, 2019. 
Este texto refere-se a uma pesquisa exploratória realizada com adolescentes na faixa etária de 16 a 18 anos que cometeram ofensa sexual atendidos em um programa de assistência a famílias em situação de violência. O objetivo é investigar o risco de reincidência sexual desses participantes por meio do instrumento ERASOR 2.0 (versão portuguesa). Trata-se de pesquisa documental, com informações colhidas dos prontuários de 12 adolescentes no ano de 2020, durante o período da pandemia da COVID-19. O instrumento é um checklist de 25 fatores que avaliam os riscos em cinco categorias: interesses, atitudes e comportamentos sexuais; histórico de agressões sexuais; funcionamento psicossocial; contexto familiar e tratamento. $O$ atendimento psicossocial a esses indivíduos em final da adolescência pode evitar processar e criminalizar essa faixa etária, prevenindo que os futuros jovens adultos sejam julgados pelo sistema criminal caso venham a reincidir a ofensa sexual.

Palavras-chave: ofensa sexual, ato infracional juvenil, processo terapêutico, adolescência.

RESUMEN

Palabras clave:

\section{ABSTRACT}

Keywords:

\section{Evaluación de la reincidencia por delito sexual cometido por adolescentes de 16-18 años}

Este texto se refiere a una investigación exploratoria realizada con adolescentes que han cometido delito sexual entre 16 a 18 años, atendidos en un programa de atención a familias en situaciones de violencia. El objetivo es investigar el riesgo de reincidencia sexual de estos participantes, utilizando el instrumento ERASOR 2.0 (versión portuguesa). Se trata de una investigación documental, con información recopilada de los registros de 12 adolescentes en el año 2020, durante el período pandémico del COVID-19. El instrumento es una lista de verificación de 25 factores que evalúan los riesgos en cinco categorías: intereses, actitudes y comportamientos sexuales; historial de agresión sexual; funcionamiento psicosocial; contexto familiar y tratamiento. La atención psicosocial a estas personas en la adolescencia tardía puede evitar enjuiciar y criminalizar a este grupo de edad, evitando que los futuros jóvenes sean juzgados por el sistema penal, en caso de que el delito sexual se repita.

delito sexual, infracción juvenil, proceso terapêutico, adolescencia.

\section{Assessment of sexual offense recidivism committed by adolescents aged 16-18 years}

This text refers to an exploratory research carried out with adolescents that have committed sexual offense in the age group of 16 to 18 years and were participating in a program to assist families in situations of violence. The objective is to investigate the risk of sexual recidivism of these participants, using the instrument ERASOR 2.0 (Portuguese version). This is a documentary research, with information collected from the records of 12 adolescents in the year 2020, during the pandemic period of COVID-19. The instrument is a checklist of 25 factors that assess risks in five categories: sexual interests, attitudes and behaviors; history of sexual assault; psychosocial functioning; family context and treatment. Psychosocial care for these individuals in late adolescence can avoid prosecuting and criminalizing this age group, preventing future young adults from being judged by the criminal system, in case the sexual offense recur. sexual offense, juvenile infraction, therapeutic process, adolescence.

DATA DE RECEBIMENTO: 12/02/2021

DATA DE APROVAÇÃO: 17/09/2021 

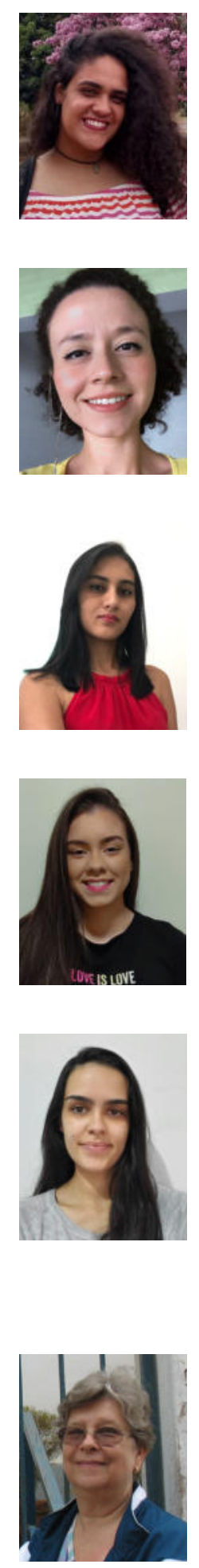

\section{Ana Clara Gomes da Silva}

Graduanda do Curso de Psicologia da Universidade de Brasília (UnB), Brasil.

E-mail: df_anaclara.gomes@hotmail.com

\section{Larissa Martins de Mello Fernandez}

Graduanda do Curso de Psicologia da Universidade de Brasília (UnB), Brasil.

E-mail: laris8m@gmail.com

\section{Ranieli Carvalho Gomes de Sousa}

Graduanda do Curso de Psicologia da Universidade de Brasília (UnB), Brasil.

E-mail: ranieligomes16@gmail.com

\section{Vanessa de Moura Pereira}

Graduanda do Curso de Psicologia da Universidade de Brasília (UnB), Brasil.

E-mail:vanessa.demoura.9828@gmail.com

\section{Andrea Schettino Tavares}

Psicóloga, Mestra em Psicologia Clínica e Cultura pelo Programa de Pós-Graduação em Psicologia Clínica e Cultura do Instituto de Psicologia da Universidade de Brasília (PPGPsiCC/IP/UnB), Brasil.

E-mail: andreaschettinog@gmail.com

\section{Liana Fortunato Costa}

Psicóloga, Doutora em Psicologia Clínica pela Universidade de São Paulo (USP), Brasil, Docente Permanente do Programa de Pós-Graduação em Psicologia Clínica e Cultura do Instituto de Psicologia da Universidade de Brasília (PPGPSICC/IP/ UnB), Brasil.

E-mail: lianaf@terra.com.br 